\title{
MODELLING OF THE RELATION OF NATURAL DISASTERS AND THE ECONOMIC GROWTH USING NEURAL NETWORK
}

\author{
N. Ebrahimi \\ MA of Economic Sciences from Tehran PNU
}

Published online: 16 July 2016

\begin{abstract}
In the recent years, the phenomenon of global climate change has approached a growing and accelerating process and the dangers caused by it are strongly threatening all the dimensions of humans' lives. It is obvious that economy and production and commerce ability of the countries are also under the influence of natural changes. But when the changes and natural challenges finds a high speed or volume, they are called natural incident or natural disaster. Natural incidents, in addition to damages to life and emotion that set upon human's heart and soul, it will also be followed by hard monetary expenses. This study, with taking some distance from theoretical models which they have expressed on this matter, has tried to model the relation of expense caused by natural incidents and economic growth using the technique of neural network. The results from data analysis with neural network show that natural incidents and the amount of expense caused by it have influence on the economic growth and through reliance on that, the economic growth can be predicted.
\end{abstract}

Keywords: Natural Disasters, Neural Network Model, Economic Growth and Development, Prediction

Author Correspondence, e-mail: nasserebrahimi60@yahoo.com doi: http://dx.doi.org/10.4314/jfas.v8i2s.105 


\section{INTRODUCTION}

In December of 2004, after the earthquake in ocean in southeast of Asia near Sumatra, Indonesia, a destructive tsunami occurred which killed over 200000 people. Several years later, in January 2010, Haiti took the lives of 230000 people by a great earthquake with the magnitude scale of 7.0 Richter. These were only two recent examples of natural disasters in great magnitude which has had much influence on the lives of people in particular countries. Through the last three decades, the number and magnitude of natural incidents have increased outstandingly. Since 1970, about 10000 natural disasters have occurred all over the world which have influenced the lives of over 7 Milliard people, and have caused over 2 trillion dollars of damage and this number is still constantly increasing. (EM-DAT-2012).

From the perspective of theories of economic growth, it is not directly clear whether the natural disasters influence the economic growth or not. The traditional neo-classic grown models predict that the temporary destruction of the country's investments leads to distance from the balanced path of growth, while endogenous growth models present less clear predictions (Kavalo and colleagues, 2013). For example, in the creative destruction theory models of Schumpeter, it is even possible that the prediction of higher rate of growth as the result of natural disasters, as a shock can be a facilitator for the investors again and promote the equity (Louisa and colleagues, 2012 and Kavalo and colleagues, 2013).

Therefore this question that whether natural disasters influence economic growth or not, must finally be investigated by experimental studies (Kavalo and colleagues, 2013). The first experimental study in this matter is presented in 1993 by AlbalaBertrand. The primary conclusion of this article is that while a minor economic growth occurs immediately after the disaster, it will barely lead to everlasting and permanent influences. After the stream of reconstruction, the gross domestic product per capita returned to the state before the disaster which was convergent with the long-term growth path. Nonetheless, these evidences were criticized by other various scientists that this claim and the experimental result of natural disasters, the features of the used and sample model of the country is sensitive.

Two decades after AlbalaBertrand (1993), various studies looked upon this discussion from the econometric perspective (Skidmore and Toya, 2002, Radatz, 2009, Noy, 2009, Loayza et al., 2012, Noy and Nualsri, 2011, Kuarsma, 2010, Gasbnor et al., 2010, and Ah and Reuven), 
nevertheless, the overall image that exists from this matter is still undetermined and unclear. Various studies have reported the negative influence of natural disasters on the economic growth (Rasmussen, 2004, Noy, 2009, Loayza et al., 2012, Skidmore and Toya, 2002). As an example, Rasmussen in 2004 showed that natural incidents have led to the average decrease of about two percent of the growth rate of gross domestic product of that same year. On the contrast, many studies have not observed any kind of influence even with considering time (Kasli and Malhotra, 2004).

This view that there is no influence between natural disasters and economic growth has been confirmed by some of the recent studies in relation between natural disasters and economic growth (Keyber and Laajaj, Kavalo, 2008 and Noy, 2011). Even though these studies have presented a good overall view, the results of experimental studies have not been systematically investigated. On the contrast, this study seeks to investigate the existing studies in relation to natural disasters and economic growth per capita using the neural network modelling.

\section{2- The Purpose of the research:}

Prediction of natural incidents on the gross domestic product

\section{3- Hypothesis:}

Natural incidents have negative impact on economic growth.

\section{4- Theoretical Basics:}

\section{4- 1- Natural Disasters}

Different interpretations have been presented for natural disasters. In the view of some of the researchers, natural disasters is a condition of collective pressure, while in the view of some other researchers, natural disasters are recognized as a period of social crisis. Also, the event that occurs in space and time and influences a part of society and causes some damages in the physical environment and the people, and that also interrupts the social performance and activity, is defined. Recent definition, from this aspect that emphasizes "a part of society", is very vast. In fact, when a disaster influences a small society, its influence is sensed by each of the members of that region. The influences might be physical-material, social-structural and cultural-spiritual (Nasreen 7, 2004:1). 


\section{4- 2- The Sorts of Natural Disasters}

Generally the word natural disasters refers to the changes which occur in any environmental conditions, in a way that causes interruption in the process of natural life of people and puts them in front of environmentally harmful, dangerous and destructive elements and factors.

The sorts of natural disasters can be categorized according to the creator source as follows:

A) Disasters which are caused by the influence of atmospheric factors; like storm, flood, hail, severe cold and frost, extreme heat, tornadoes, dust...

B) Disasters which are caused by changes on the surface of earth; like avalanche, landslides, earth shaking, mudslides and...

C) Disasters which are caused by shake or movement of different parts of layers of earth; like earthquake, volcano and... (Amirani, 1992, 56-61).

For an increasing number of people, the threat of natural disasters is a permanent and ominous souvenir. Flood, storm, earthquake, drought and conflagration are natural disasters which have destructive social effects across the world. The wider economies are not immune against the positive and negative natural disasters; because the frequency and magnitude of the destruction is increasing in the recent times.

On the other hand, one of the most important subjects of discussion on the economy, in the years after the Second World War especially in developing countries is the matter of economic growth. The economic growth and development is the important purpose of macro economy of each country and for achieving economic growth, many factors are influential. The survey of changes of related discussions to the economic development of societies, with the purpose of achievement to appropriate criteria for comparison of economic condition of different regions and representation of appropriate patterns of planning of the development, has led to the formation of patterns of economic growth and their evolutionary process.

One of the most important patterns of growth is the new-classic growth pattern which is called the growth pattern of Solow-Sowan, due to three major Solow (1956) and Sowan (1956).

Before discussion about some of the possible scenarios of the influences of macro economy of natural disasters, we start with a simple model of growth for showing the theoretical relation between natural disasters and economic growth. Since the rate of growth per capita is the point of attention for us; we assume that production in economy is described based on the following Cobb-Douglas production function: 
Formula (1)

$y_{t}$ : Production Output Per Capita at the Time of $\mathrm{t}$

$A_{t}$ : The Surface of Existing Technology

$k_{t}$ : Ratio of Stock-Physical Work

$h_{t}$ : Ratio of Stock-Human Work

The natural disasters may influence these stimulants of economic growth. On one side, the natural disasters decrease the accumulation of physical and human stock through the drop in the savings rate due to private expenses on the medical cares and increase in emergency expenses. In that same time, the rate of depreciation caused by the inured and destructed physical stock increases. In addition to this, the accumulation of human stock decreases after the natural disasters in large magnitude through losing skilled work forces due to the increase of the rate of disability and the number of deaths caused by the disaster. Also the migration after the disaster, may lead to further decrease in accumulation of human capital and its future, particularly in the case of skilled workers who have more sources for movement (Klomp \& Valckx, 2014).

Therefore the general influence of natural disasters on the ratio of stock-work is relatively ambiguous and in fact it depends on the fact that between the decrease of population and destruction of the amount of physical or human stock, which is the dominant influence. The existing literature show that the influences of depreciation is most probably more important than the influence of population in many countries. Loayza at al (2012) show that the strong events are most probably for putting the economy in the path of lower growth or entrapping them in a low-level equilibrium; when they find themselves near a least threshold of stock in the period before the disaster.

In addition to this, the influence of natural disasters on the development of technology form the theoretical view is not directly clear. On one hand, the natural incidents may destroy the $R \& D$ possibilities and or the education opportunities while working and therefore have a negative influence on the rate of technology growth. Nevertheless, on the other hand, when after a natural disaster, the more advanced technologies are replaced by the existing technologies, it may have a 
positive influence on the level of technology of a country. Theoretically, with referring to the influences of macro economy of natural disasters in large magnitude, the prediction is not clear. Klomp \& Valckx (2014) proposed 4 possible scenarios for the evolution of long term economic growth per capita, after the occurrence of a disaster in the titles of their article's contexts.
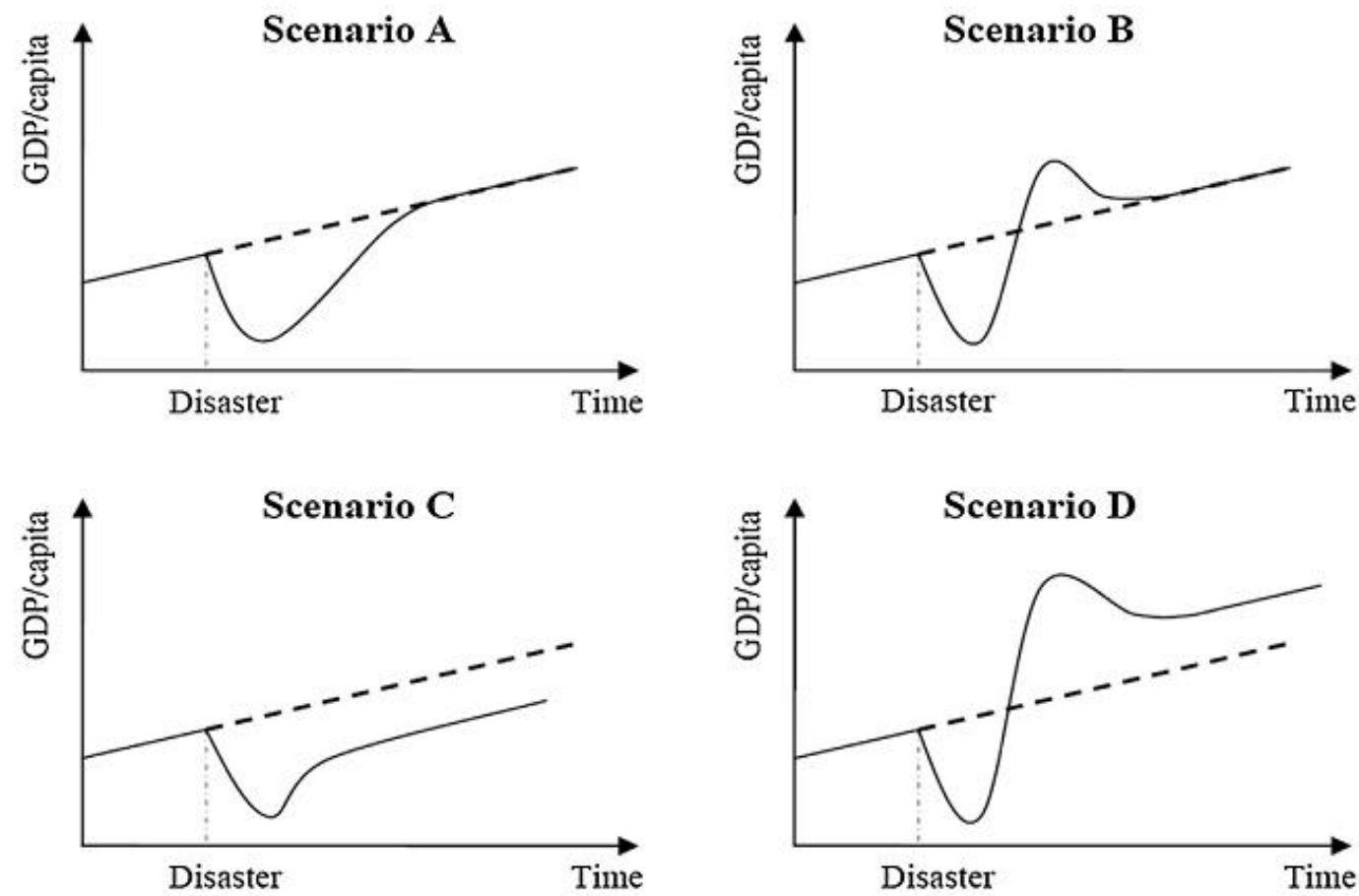

Fig.1. The Four Existing Scenarios of the Influence of Long-Term Output of Natural Disasters Source: Article of Klomp \& Valckx (2008)

In all conditions, a primary drop in the gross domestic product per capita in short term is common due to the destruction of production capacities of a country and interruption in economy. The scenarios $\mathrm{A}$ and $\mathrm{B}$ both argue that natural disasters have only a temporary influence on the economic growth. In both scenarios the ratio of stock to physical and human work drops in short term. Nevertheless, regarding the return of stock after the disaster, the direct foreign savings and investment are triggered in the stream and in its own turn, the rebuilding investment is created which increases the ratio of stock-work again. Nevertheless, in long term it is the depreciation of larger stock than replacement investment that brings back the income into its long-term growth path. Another explanation for scenario B is that the foreign help input is 
temporarily stopped in a particular point of time and it causes the GDP per capita to take a step back to the primary balanced growth path.

In the scenario $\mathrm{C}$, there is a permanent decrease in the ratio of stock-work, majorly caused by monetary limitations which are appeared by the families and the private section which has led to the investment in stock for work. The country reaches to a new long-term growth path which is lower than the primary path. Finally, in the scenario D, there is long-term positive influence from natural disasters on the income, because the stock with better technology is replaced by destructed or ruined stock. The authors argue that the natural disasters in large magnitude can be used as a facilitator for promoting the stock with a more generator version.

In addition to this, different disasters, create different conditions; for example an earthquake is more plausible for being related to scenarios B and D which are caused by an outstanding rebuilding which may create an efflorescence and finally technological changes. On the opposite, the scenarios $\mathrm{A}$ or $\mathrm{C}$ are more related to drought, because the harm and loss is usually limited to annual or seasonal production. In addition to this, most of the climate and weather disasters occur often and only in special times of the year which makes them more predictable (Skidmore and Toya, 2002).

Also some efforts are done for the explanation of differences in the gained results across the countries. As an example, developing countries lean toward a more vulnerability from the region of natural disasters, in a way that they have a less diversity and a more tendency toward reliance on the agriculture section. In addition to this the developing countries don't have an appropriate policy for the disasters including its decrease meaning the decrease of the danger of occurrence of harmful disasters, its adaptation and compromise meaning the rebuilding of economy apart from the disaster-prone activities and grading the physical infrastructures to resistance against the influence of the event (Loayza and et al, 2012).

The natural disasters, in addition to the direct influence on the drivers of economic growth may also have an indirect influence on the development of economy. As an example, disasters may increase the accumulation of the government's debt in later consequences. According to the existing literature, the natural disasters influence the financial property from three channels: First- the base of government's income may weaken after the natural disaster, therefore a recession in the activity of economy implicates the decrease of financial income. In addition to this, the tax administration issues and collecting it may get interrupted after the natural disaster. 
Second- the government encounters an increase of pressure on public expenses caused by the unexpected expenses in the operations of short term emergency help. Third- the government must repair the public infrastructures like roads, bridges, airports, ports and public buildings which have been destructed after the natural disaster. Also the natural disasters in large magnitude may seriously harm a country's competition caused by the destruction of production capacities. As a result, the increase of imports, along with the decrease of exports will lead to worsening the balance of a country in trade. This trade deficit might get worsen; in case that an output of short term stock after the disaster exists as a result of lack of trust in increasing future refund. Worsening of trade level might create more or less an outstanding downward pressure in the currency rate.

I addition to this, natural disasters may not only have economic consequences and brig about also political consequences. The increase of possibility of political instability is possible after a disaster. This is its own turn may lead to more lack of political finality and thus the decrease of economic activity (Klomp \& Valckx, 2014).

\section{5- A Review on the Literature of the Subject:}

Albala-Bertrand (1993) has examined the relation between a natural disaster and its potential influences on the growth rate by a simple model of macro economy and has used the crisis data in 26 countries at the period 1960-79. He has concluded that the disadvantage of stock probably doesn't have an important influence on growth but the relatively mild increase of government's expenses may prevent the decrease of the product's growth rate.

Seluk \& yeldan (2001) investigated the influences of macro economy of 1999 earthquake of turkey and used the public balance model for evaluating the influence of earthquake on the variables of macro economy in long term and short term. The results have shown that the primary influence of earthquake on gross domestic production, regarding the government policies and international helps fluctuates from negative 4.5 to positive 0.8 percent of gross domestic product. They acknowledge giving subsidy as the best method for covering the disadvantage of stock which is financed by foreign help.

Skidmore and Toya (2002) have investigated the long term influence of natural disasters on the economic growth. They calculated the abundance of natural disasters for each country in the period of 1960-1990 and normalized according to each country's space. They have also 
determined the correlation of this criteria with economic growth, accumulation of physical and human stock and efficiency of all factors.

Benson (2003) has used comparative cross-sectional data about the performance of gross domestic production of 115 countries in the 34-year period of 1960-1993 for the study of the influences of natural disasters on long term growth and has figured out that the countries which experienced the occurrence of natural disasters repeatedly in the mentioned period received lower growth rate.

Kirigia et al (2004) have investigated the economic influences of human wastes caused by the natural disasters and have estimated the influence of natural disasters on gross domestic product using a Cobb-Douglas function with specification of mutual algorithmic model and crosssectional data in 26 African member countries of the World Health Organization. The results of the study have shown that the death of one person by the natural disasters has decreased the gross domestic product by an amount of 0.018 dollars.

Anbarci et al (2005) have related the wastes of earthquakes to the income per capita and level of domestic inequity (based on the Gini coefficient based on earth) and have examined their theoretical model with evaluating 269 huge earthquakes which occurred between the years 1960 to 2002 on earth and have also considered other influencing factors on the destructive power of earthquakes including their magnitude, depth and closeness to population centers. Based on a theoretical model they predict that, with keeping the appropriate control variables (like magnitude, population, earth space, distance from the center of earthquake and other factors) consistent, the number of wastes by earthquake must be a decreasing function of the level of a country's income per capita and equity and verify the predictions of the theoretical model using a negative two-sentenced estimation method with random and consistent estimators.

Noy (2007), in an article with the title of "The Macro Economy Consequences of Disasters", states that countries with higher literacy rate, better institutes, higher annual income, higher degree of openness of trade and high levels of spent expenses of government can better stand against the primary shock of disaster and prevent the spread of secondary influences. Also the countries with more currency savings and higher levels of domestic value, but with more powerful, lower and open stock accounts can better tolerate the natural disasters.

Kellenberg. A and Mobarak. A (2008), using the panel data of the country-year, states the reverse $\mathrm{U}$ relation between the risk of disaster and income. From the political perspective, this 
shows that, for countries with the least development, we cannot assume the twofold purposes of prevention of risk of disaster and economic development as supplement to each other for all forms of natural disasters.

Cavallo \& Noy (2010) examine the long term and short term influences of natural disasters on the economic growth using the combination of information gained from the comparative case studies and focus their attention on the special influences of unexpected huge disasters on the domestic output. As a result of these studies we find out that big events have a negative influence on both outputs in short term and long term and using the exact deduction method, it has been showed that these results are meaningful from the statistic point of view. However the smaller disasters, opposite to huge disasters don't have a tendency to outstanding influences nor in long term neither in short term.

Bang.vu \& Noy (2010) investigated the influence of disasters on the growth of production in Vietnam. They estimated the influences of disasters on the economy using provincial information for primary and secondary industries and Blundell-bond method. The more killing disasters had less influence on growth but the disasters which have led to destruction of estate and stock, have promoted the short term influences. Also the disasters had different influences on production in geographical regions and we can acknowledge that its reason is the way of relocation with the center of Vietnam.

Kim (2010) investigates the influences of disasters on long term economic growth according to the study of Skidmore and Toya (2002) for the period 1990-2004 and using the solo model's frame stated in the article of Ekoyama (2003) and seeks to verify the influence of Schumpeterian process of creative destruction on economic growth which is mentioned in the study of Skidmore and Toya. Kim states that accumulation of human stock and development of technology are caused by the disasters of min paths which through them the disasters influence the economic growth and there is a positive correlation between long term economic growth and the abundance of disasters.

Asgary et al (2011) investigates, in an article titled "The Repairing of Disasters and Business Continuity after the 2010 flood of Pakistan, the influences of this flood on small businesses and factors which influenced the retrieval of disasters. The findings show that 90 percent of businesses are retrieved six months after the flood; but most of them about 70 percent of them were along with harm and only a few of them in about 22 percent were located in the old level or 
better condition. On the other hand, it must be stated that factors like the average monthly sale, the experience of past events, reliance on water, reliance on transportation, personal saves, harm to business installations, harm to the existing items, recognition of repairing priorities, family and friends' support, cooperation of clerks and cooperation in retrieval have important influences on the repairing time. The results show that ordaining governmental and non-governmental supports can increase speed, quality and sustainability of retrieval of small businesses' disasters. Loayza et al (2012) investigates the influences of natural disasters on growth separately by disasters and economic section in an article titled "Natural Disasters and Growth: Surpassing the Average". Through using and performing a dynamic overall method by the estimator panel for the collection of panel data related to period of 1961-2005, three perspectives are resulted which include: 1) influencing of disasters on growth is not always negative and is different with changes during different events and economic sections. 2) Even though the incidents in the average level can have a positive influence on some parts, but it's not so about strong incidents.

3) Growth in developing countries in comparison to developed countries are along with more sensitivity against the natural disaster.

Miao and Popp (2013) investigate in an article, the influence of three kinds of natural disasters including earthquake, drought and flood on the relative decrease of technology. This research is the first report of natural disasters in technology innovations and also the first effort for experimental study of the compatibility of reactions to climate changes across various sections across the country. Our experimental analysis using a panel model for 30 countries during a period of 25 years reveals the stimulating influence of compatibility of natural disasters on the flow of registration of innovation which can decrease the dangers of similar disaster. For all the kinds of related innovations in here, we find some evidence that the amount of innovation of decrease of danger in a country increases with the intensity of recent natural disasters. These findings show that people are constantly learning from their experiences of disasters. In addition to this, the study shows that the innovators respond not only to domestic shocks but also to natural disasters occurred in other countries; even though the second is very small and is not pervasive to all kinds of innovations.

Klomp and Valckx (2014) presented an article titled "Natural Disasters and Economic Growth". We must mention that during the past two decades, the number and intensity of natural disasters has increased outstandingly. Many of the experimental studies have tried to estimate the 
influence of this increase of process on economic development. This article also investigates the influence of natural disasters on the growth of real gross domestic product per capita using a regression analysis on the vast amount of experimental studies. The presented studies are very different according to the kind of considered disasters, sample countries, time period, model features, model estimations and output of publication. After many experiments on the results, we conclude that natural disasters have an actual negative influence on economic growth which increases during the period of our analysis. Nevertheless the intensity of disasters and the used country samples are different and it is particularly clear that climate disasters in developing countries have an outstanding inappropriate influence on economic growth. On the other hand, we also found evidences that part of the negative influence of natural disasters found in the studies were created by the bias in the estimation.

Klomp (2014) investigates the influences of natural disaster in large magnitudes on the lack of paying debt and shortcomings of commercial banks in an article titled "Financial Breakability and Natural Disasters", using the data of over 160 countries in a period of 1997-2010. The financial consequences of natural disasters may be a pressure and threat for the stock of a bank by important influences on paying their debt. After many experiments due to sensitivity, the results of the primary findings of research show that the natural disasters increase the possibility of lack of paying bank debts. The gained results obviously show that natural incidents are an outstanding threat for liquidity; in addition to this, the influence of natural disasters depends on the measure and scope of the disaster, restrict financial rules and financial level and economic development of a particular country.

After the earthquake of Rudbar (1996), a delegation from the United Nations and the Islamic Revolution Housing Foundation estimated the damages and rebuilding needs of the destructed regions. According to the above study, except 50-million-dollar currency damage to industrial organizations, the overall damages caused by the earthquake of Rudbar were estimated more than 1638 Milliard Rials, 76 percent of which has been related to the housing section, 0.8 percent related to life tools and goods of affected households by earthquake and the rest related to the infrastructure productive sections and other economic activities. About 6.8 percent of the mentioned damages had indirect nature.

Mousa Kazemi (2004) has investigated the compensation strategies of damages of natural incidents in Iran and world in a study and believes that adoption of methods based on 
management of crisis are not solely influential for compensation of damages caused by incidents, but a collection of policies must be performed. Representing public insurance coverage of natural incident and changing the damages caused by natural incidents in country on the basis of economic indexes are among these policies. The occurrence of a disaster in national dimensions, in addition to creating irreparable life damages, strikes two dangerous hits to the economic body of a country's economy. One the direct damage that strikes the national estate and wealth and the other deviation of sources and national efforts from development and achieving ordinary standards of life which is performed for the compensation of damage and reaping the harmful influences of the disaster. Therefore it reminds us of the necessity of creation of correct perspective and necessity of comprehensive and strategic planning about managing disasters more than before. Jahangiri and Tayebi (2006) acknowledge some of these related strategies as the guidance of single-product economy toward the multi-product economy in vulnerable regions and the development of economic activities against the disasters in the at-risk regions.

Asgary (2008) states that according to distinct changes which has happened in the structure and organization of cities, they have become very vulnerable against the many unexpected incidents. The growing population, industrial focus, spread of poor areas, many women, children and disabled and old people, the appropriate background of creation of technological crisis, nuclear dangers and many other factors are the issues that he states for the vulnerability of cities.

Sadeghi and Emamgholipour (2008) have investigated the influence of natural disaster on the non-oil gross domestic product in Iran. In order to do so, they have used the method of auto regression with distributed lags in the time period of 1959-2004. The results of the estimation of short term and long term patterns show the negative influence of these disasters on economy and the U-shaped relation between the amount of damages of natural disasters and the non-oil gross domestic product.

Aghabakhshi (2009) states that the private section of commercial institutes and companies have had positive and influential usages in unexpected incidents in addition to profit-seeking tendency. He has evaluated the responsibility of institutes on the decrease of natural disasters by looking to the country of Bangladesh. Private section's usages were considered both from the perspective of cooperation of private section in preparation for decrease of influences and consequences of disaster and from this perspective that it can be an appropriate bed for promotion of this section's activity in areas that lead to economic and financial exploitation. 
Askarizade et al (2009) state that it is often conventional that the planners of development and crisis work separately and this issue has led to discordance in the matter of planning the development and crisis and only a few countries that have comprehensive plan of managing the dangers and disasters in their development plan have paid attention to the phase of preparation and most of the attentions are dedicated to the phase of opposition to the crisis.

One of the important subjects that most of bug cities of the world face is the subject of natural incidents. According to the unexpected nature of these incidents and the necessity of fast and correct decision makings and performing the operations, the basic and theoretical principles have created a knowledge under the title of crisis management is; this knowledge is named after the collection of performances that are operated before, during and after the crisis in order to decrease the influences of these incidents. Ghanavati et al (2009) try to investigate the empowerment process of crisis management in order to decrease the natural disasters (earthquake) in the city of Khoramabad in an article with the descriptive analytic approach and survey. We can refer to the decrease of influences and damages caused by natural incidents particularly with the usage of correct management. Also the tool of GIS has been used in the investigation and data analysis.

Nasiri and Alameh (2009), in an article titled "Drought and Stable Development" states that the growing process of population especially in the last few decades, increase of demand for essential needs like food, clothing and housing, economic ravages and market and comprehensive poverty are shaped into a frame of a complex multi-variable equation; whose appropriate solution for solving it seems to be difficult. The existence of natural disasters like drought, flood, storms and... make the solution of the issue more complex and encounter the operation of correct management with problems. On the other hand, immediately after the achievement to relative stability, a part of factors, especially the events that are unexpected and humans can't have complete control over them, will cause interruptions in the achieved stability. Drought is one of these factors and its correct management (before, during and after the occurrence of drought) seems to be necessary in order to achieve the comprehensive development which is called the stable development. It is necessary for all especially the experts to plan an edited and distinct planning in order to control drought and decrease the damages caused by it so that, on one hand, the caused damages would be compensated and on the other hand, some steps would be taken in the direction of stable development. 


\section{6 - Methodology of research:}

\section{6 - 1 - Methodology of Research}

The main purpose of conducting this research is the prediction of the influence of natural incidents on gross domestic product.

This research from the perspective of purpose is a usage which using the statistical and mathematical methods and economizing predicts the influence of natural incidents on the gross domestic product using the Bayesian neural network model. In this method the amount of damages of incident is used as input data. Also the expected output data can be different models of gross domestic product or the economic growth rate which of course here, the rate of the countries' gross domestic product are used according to milliard dollars. For conducting the research the information of ten countries of Iran, China, Malaysia, Egypt, Turkey, England, France, America, Germany and Russia were used, the amount of damages of occurred incidents in these countries in the period of 1970 to 2013 against the amount of gross domestic product of the country in that year have been two-component which were used for the creation of the model. For the analysis of the adata, the software of MATLAB14 was used.

\section{6 - 2 - The Structure of Represented Network}

In the present research, multi-layered neural networks with the after the publication of Bayesian error algorithm has been used due to representing the higher exactness, a neural network includes input, middle and output layers. In this research the neural network with three layers and 5 neurons in the input layer is used. Image 2 shows the network structure which is used. 


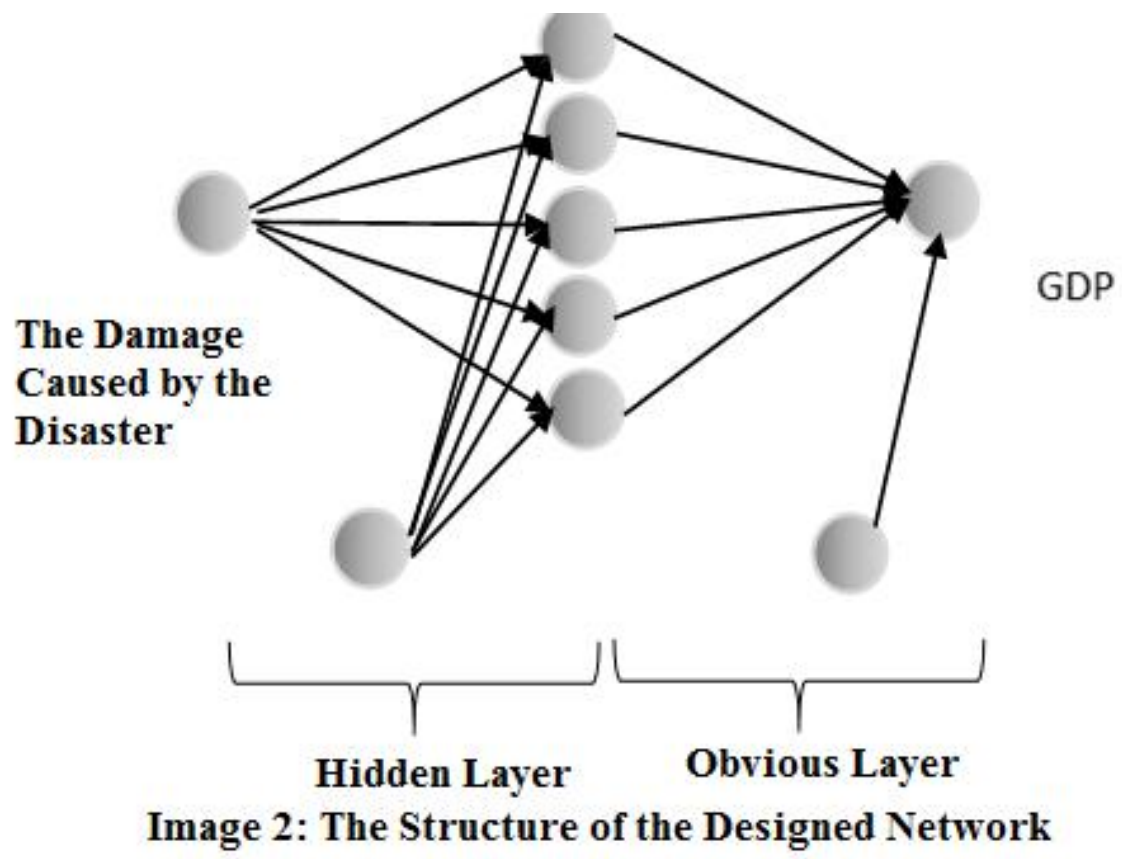

The needed data includes the expenses caused by the incident as input data and gross domestic product of the country as the output data which are categorized in a data set including 144 data. 21 data $(15 \%)$ of the data which are chosen totally randomly among the data, are used for the education of the network. 14 data $(10 \%)$ are also used for validation of network. Also from the 144 primary data, 4 data are separated from the primary data for evaluation of the model. The after publication of Bayesian error equation was sued for education, weights and biases of each layer, while the equation of transfer in the first layer was sigmoid and in the second layer was purelin. The process of education continues to the point that the least Mean Squared Error (MSE) is achieved. At any moment of the education of network, the weights and biases change randomly and by the education algorithm itself for better result. The results of prediction is compared with real data using designed network. Image 3 shows that the best result caused by education of network has occurred in the sixth epoch and its exactness has been 3.6037. 


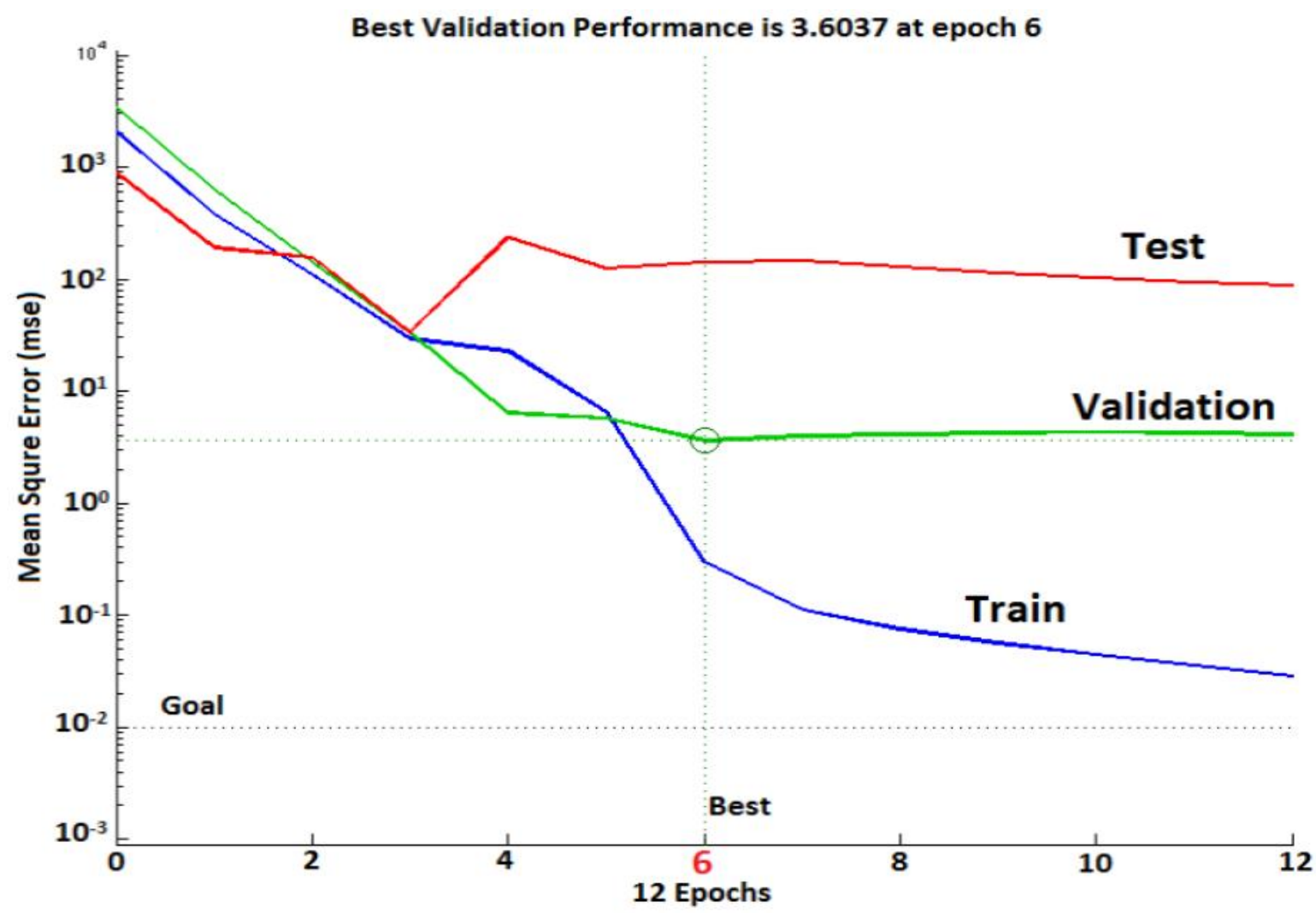

Fig.3. The System of Education Performance, Validation and Evaluation of Artificial Neural Network

The image 4 shows the comparison of real and predicted numbers by the model in each part of the data which includes education, validation and evaluation data. The gained model of neural networks whose fitness can be seen in image 4, represents the appropriate accordance of the model with real data. The regression coefficient $(\mathrm{R})$ which shows the correlation between input and output data for education, validation and evaluation data are $0.9998,0.9973$ and 0.9510 . 

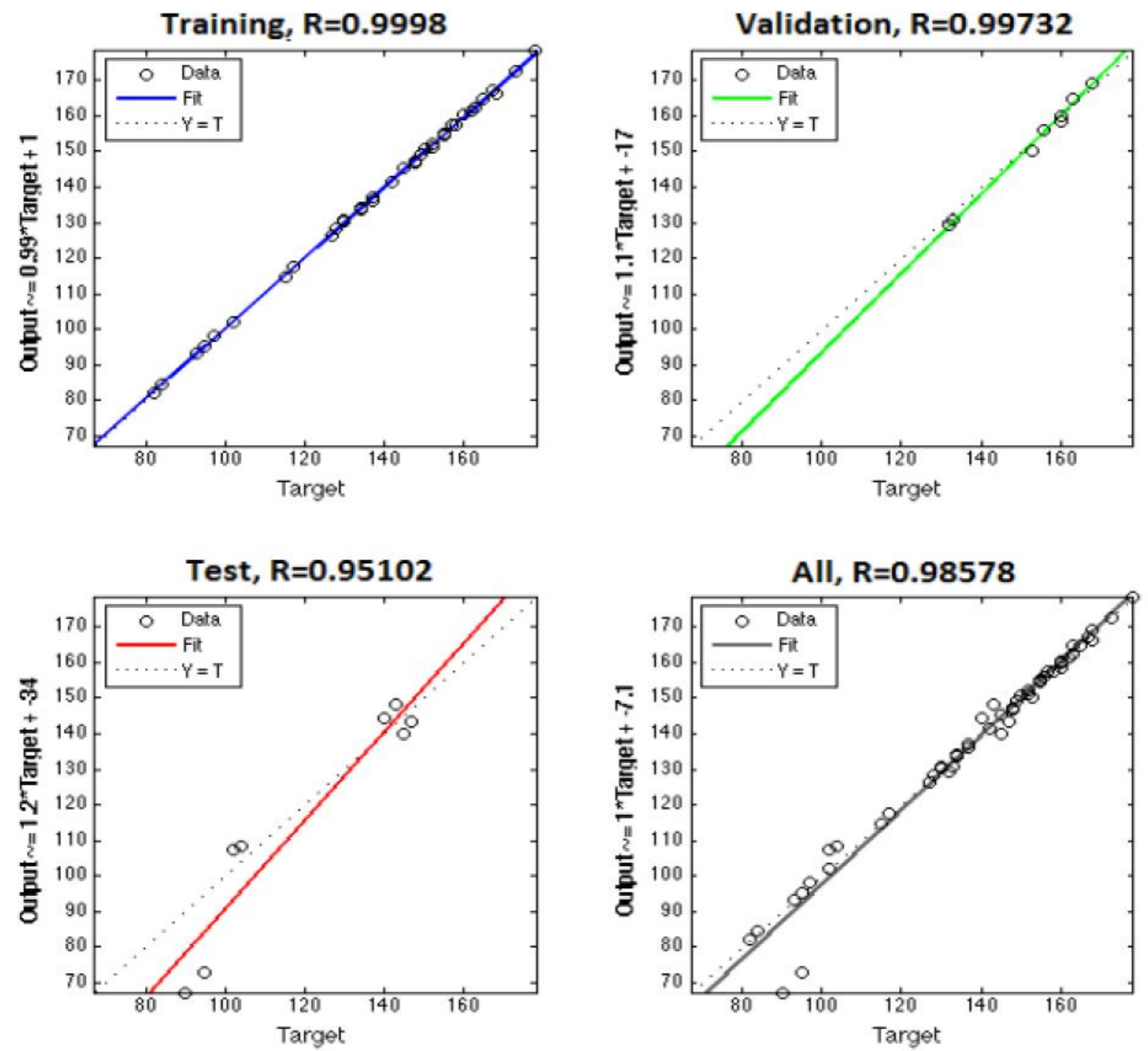

Fig.4. The System of Prediction of Data

As it was mentioned, the education of neural system continues to the point that the least amount of error is gained, image 5 shows the error of data resulted from neural network model with real data. It is obvious that the amount of resulted error is very little. 

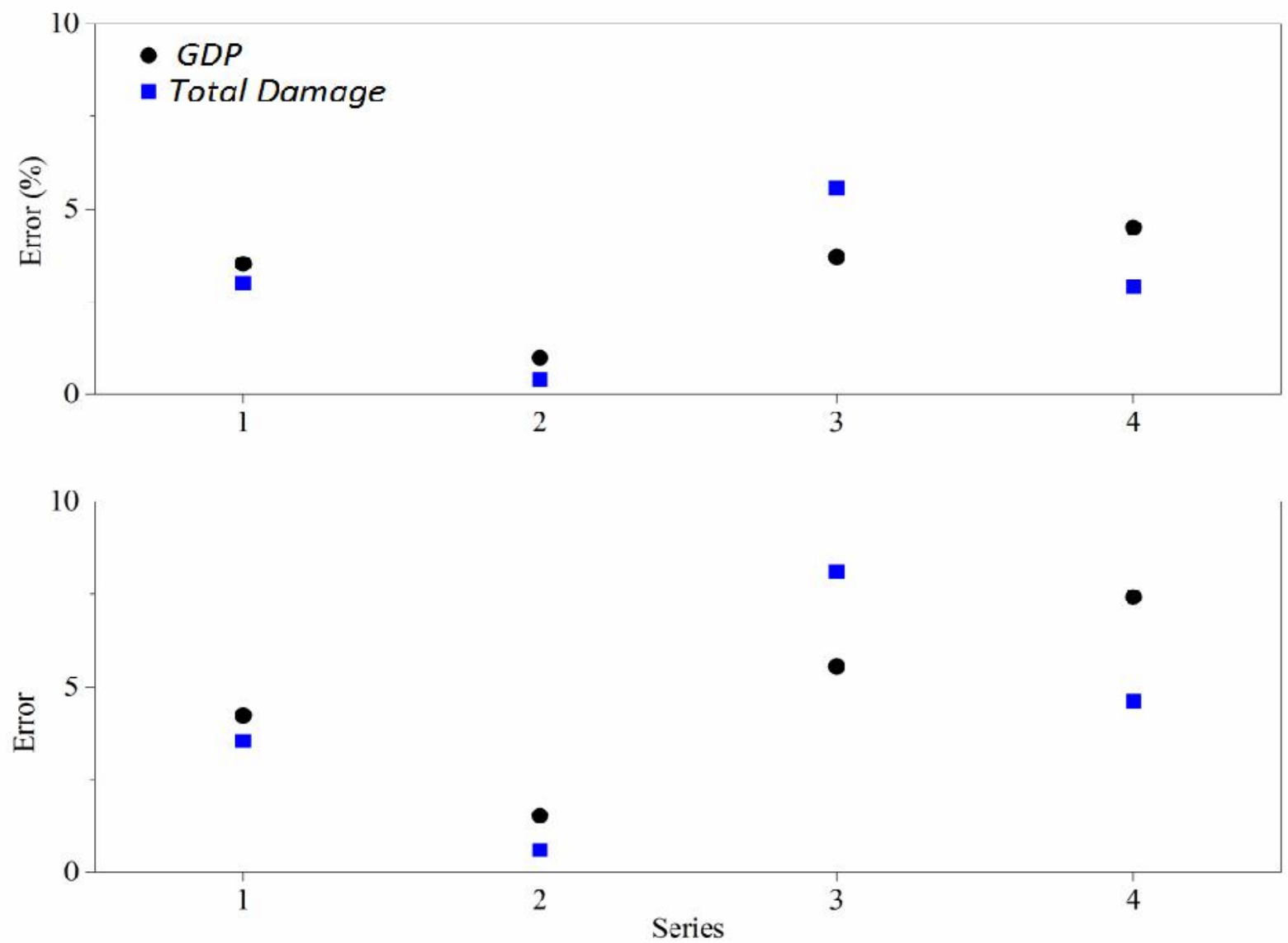

Fig.5. The Calculated Error between the Predicted and Real Data

In image 6 which is a comparison of real and predicted data, it is clear that the predicted data has a very good accordance with real data. In image 6 , the 4 data that are intentionally separated from the other data for the final validation of the model are predicted using the model; it is clear that the presented model could predict these numbers very perfectly. 


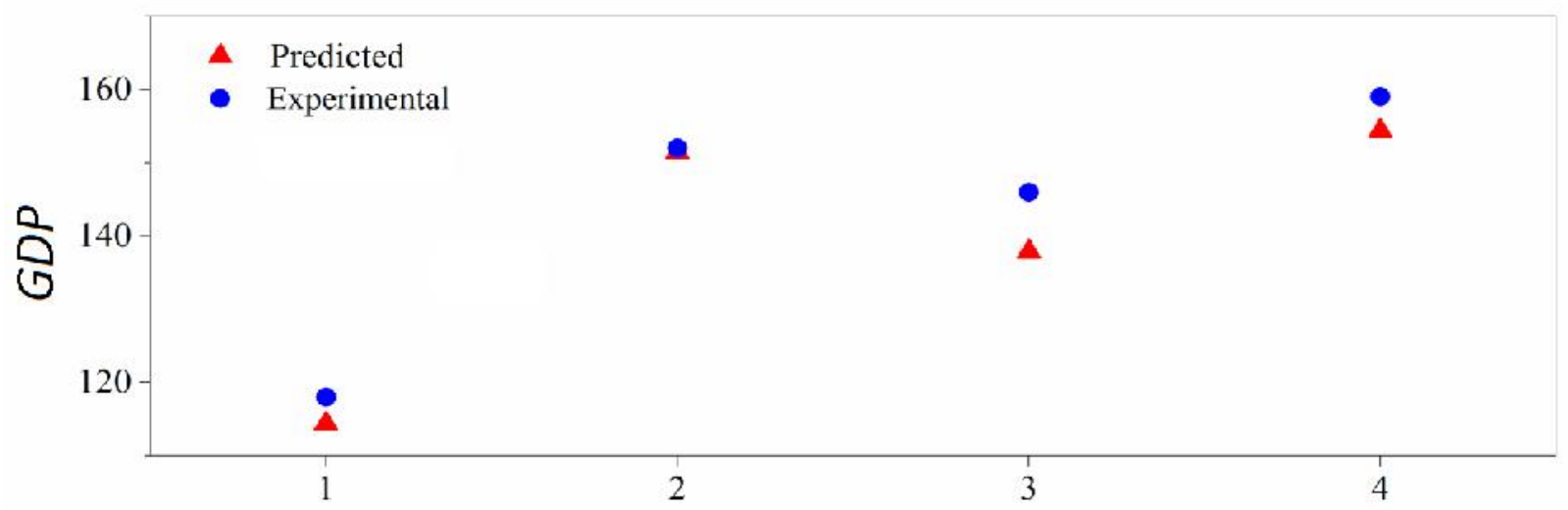

Fig.6. The Diagram of Comparison of the real Performance of the Model

\section{7 - CONCLUSION}

Study about the influences of natural disasters on the economic state of the countries is one of the developing subjects in recent researches and regarding the daily increase of disasters and their magnitude, research on this matter has been the point of attention of many economic researchers, policymakers and planners. In this article also the influences of natural disasters on economic growth of selected countries was studied regarding the increase of disasters and destructive influences caused by it. In this research the relation of these two variables were modelled using the technique of data analysis with neural network.

Usually the occurrence of incidents has had deep influences on life, sustenance and social processes of people's life and has caused the imposition of many losses and damages to societies and human activities and has destructed the infrastructures, equipment and production facilities. On the other hand, also in developing countries due to weakness of non-military defense organizations and the breakability of economics, the enough capability for standing against the huge financial burden of damages caused by the disaster is not given. Therefore when incidents occur, the resources are moved toward them and are spent in the direction of protection and savory of people and it postpones the development of regions and sometimes stops the development and growth process and or even reverses it.

The collection of studies show that we should focus on prevention of crises and managing them for preventing the decrease of economic growth under the influence of natural incidents and 
disasters; so to prevent the occurrence of crises. On one hand, because the influence of government expenses on economic growth is negative; therefore according to theoretical expectations, increase of government expenses for compensation of damages caused by crises leads to the economic growth of injured countries. Thus the crises have not provided the opportunity of economic growth and development. Anyway we must state that in all the countries of the world, the natural disasters are presented as an obstacle in the path of national production and economic growth and in case the economic planners and decision-makers want to reach a distinct economic growth, they must pay attention to the obstacles of natural disasters which have an inhibitory influence on the path of reaching economic growth and plan in a way that regarding this limitation, the pleasant economic growth is targeted and planned. Finally this suggestion must be presented that long term and slow changes like drying of lakes, decreasing rainfall and increasing temperatures and its long term influence on the conditions of production and trade and accordingly on the economic growth must be modelled and investigated.

\section{RESOURCES}

1. United Nations Development Programm and the United Nations Centre for Human Settlements in Cooperation with the Islamic Revolution Housing Foundation (1996), Economic Losses of 1990 Earthquake in Northern Iran, Islamic Revolution Housing Foundation.

2. Aghabakhshi, Habib (2009), "Corporate Social Responsibility in Natural Disaster Decrease (Experiences from Bangladesh)".

3. Jahangiri, Katayun and Tayebi, Seyed Jamal al-Din, "Strategic Planning Approach in Reducing the Economic Consequences of Natural Disasters", Monitoring Quarterly, Year Five, 2006, 4: 281-287.

4. Hassanzadeh, Ali and the Ahmadi, Azam., the Effect of Stock Market and Economic Growth. Journal of Money and the Economy, 2009, 2: 31-52.

5. Sadeghi, Hossein and Emamgholi pour, Sara, "The Effect of Natural Disasters on Iran's nonoil GDP", Economic Research, 2008, 83: 115-136.

6. Askarizadeh, Seyed Mohammad, Mohammad Nia Gharaei, Sohrab and Zohoor, Mojtaba (2009), "Disaster Management Planning and Environmental Hazards towards Sustainable Development", the Fourth International Conference of Islamic World Geographers. 
7. Asgari, Vahid. (2008), "The Vulnerability of Urban Areas to Natural Disasters in Developing Countries".

8. Farahmand, Shekoofeh and Badri, Foroozandeh Sadat (2012), "The relationship between Integration and Economic Growth in Selected Asia-Pacific Countries", Journal of Economic Research of Thought.

9. Ghanavati, Ezatollah, Ghalami, Shebn and Abduli, Asghar, "Making the Managing of Urban Crisis Capable for Natural Disaster Decrease (Earthquake) Case Study: Khorramabad Town", Journal of Physical Geography, First Year, 2009, 4: 15-24.

10. Musa Kazemi, Seyed Jamal, "A Comparative Study of Methods of Compensation Arising from Natural Disasters in Iran and the World", Journal of the Insurance Industry, 2002, 65: 2958.

11. Albala-B. Natural disaster situations and growth: a macroeconomic model for sudden disaster impacts. World Development, 1993, 21, 1417-1434.

12. Anbarci, N, Escaleras, M, \& Register. Earthquake fatalities: The interaction of natural and political economy. Journal of public economics, 2005, 89: 1907-1933.

13. Asgary, A. Imtiaz Anjuma, M. Azimi, N. Disaster recovery and business continuity after the 2010 flood in Pakistan: Case of small businesses. International Journal of Disaster Risk Reduction, 2012, 2: 46-56.

14. Benson. C. (2003). Macroeconomic concepts of vulnerability: dynamics, complexity and public policy, In G. Bankoff, G. Frerks and T. Hilhorst, mapping vulnerability: disaster, development and people.

15. Cavallo, E. Ilan, n (2010). The economics of natural disasters. IDB working paper series, wp124.

16. EM-DAT. The OFDA/ CRED international disaster database in: www.em-dat.net, universite catholique de Louvain- Brussel, Belgium.

17. Kellenberg, D, Mobarak.A. Does rising income increase or decrease damage risk from natural disasters? Journal of Urban Economics, 2008, 63, 788-802.

18. Kim, Ch. The effects of natural disasters on long-run economic growth. Michigan Journal of Business, 2010, 41: 11-46.

19. Kirigia, J, Sambo,L,.\& Aldis,W,.\& Mwabu,G.( 2004). Impact of disaster- related mortality on gross domestic product in the WHO African region, BMC emergency medicine, 4. 
20. Klomp, J. Financial fragility and natural disasters: An empirical Analysis. Journal of Financial Stability, 2014.

21. Klomp, J. Valckx, K (2014). Natural disasters and economic growth: A meta-analysis.

Global Environmental Change, G Model JGEC-1261; No. of Pages 13.

22. Loayza, N. Olaberria, E. Rigolini, J. Christiaensen, L. Natural disasters and growth: going beyond the averages. World Development, 2012, 40, 1317-1338.

23. Miao, Q. Popp, D, Necessity as the Mother of Invention: Innovative Responses to Natural Disasters. NBER Working Paper, 2013, 19223.

24. Noy. Ilan. The Macroeconomic Consequences of Disasters, SCCIE WORKING PAPER, 2007, 07-15.

25. Noy, I. Bang Vu,T. The economics of natural disasters in a developing country:The case of Vietnam. Journal of Asian Economics, 2010, 21, 345-354.

26. Seluk. Faruk, E.yeldan. on the economic impact of the August 1999 earthquake in Turky: A first assessment, applied economics letters, 2001, 8: 483-488.

27. Skidmore, M. Toya, H. Do natural disasters promote long run growth? Eco-nomic Inquiry, 2002, 40: 664-687.

\section{How to cite this article:}

Ebrahimi N. Modelling of the relation of natural disasters and the economic growth using neural network. J. Fundam. Appl. Sci., 2016, 8(2S), 1677-1699. 